\title{
Long-term safety and stability of gold coil fiducially markers in non-small-cell lung cancer image-guided radiotherapy
}

\begin{abstract}
Background: Fiducially markers aid in tumor localization during radiotherapy of lung cancer. We investigated the long-term stability and safety of gold coil fiducially markers in non-small cell lung cancer (NSCLC) patients.

Methods: Markers were implanted at our institution in 8 patients included in this analysis who underwent either conventionally fractionated radio chemotherapy or stereotactic body radiotherapy (SBRT, in one patient). Follow up CT scans were used to assess the coil stability.

Results: 15 out of 19 fiducially remained in the same anatomical location with an average follow-up of 2.9 years (range 4 months to 6.5 years) after implantation. None of the markers caused any toxicity.

Conclusion: These data illustrate that image guidance using fiducially gold coil markers is feasible in NSCLC radiotherapy with excellent long-term marker retention rate and procedural safety.
\end{abstract}

Volume 3 Issue I - 2017

\author{
Leonid B Reshko,' R Wesley Shepherd,'2 \\ Elisabeth Weiss ${ }^{3}$ \\ 'Virginia Commonwealth University School of Medicine, USA \\ ${ }^{2}$ Division of Pulmonary and Critical Care Medicine, Virginia \\ Commonwealth University Health System, USA \\ ${ }^{3}$ Department of Radiation Oncology, Virginia Commonwealth \\ University Health System, USA
}

Correspondence: Elisabeth Weiss, Department of Radiation Oncology, Virginia Commonwealth University School of Medicine, Richmond,VA 23298, USA, Tel (804) 8287232, Email elisabeth.weiss@vcuhealth.org

Received: April 22, 2017| Published: May 22, 2017

Keywords: lung cancer, NSCLC, fiducially markers, image guidance, IGRT

\section{Introduction}

Accurate radiation treatment delivery in non-small cell lung cancer is technically challenging. While significant improvements in imaging technology lead to improved tumor delineation, other challenges such as respiratory and cardiac-induced motion, setup inconsistencies, and volume changes and deformation result in significant uncertainties when it comes to targeting the tumor and minimizing normal tissue toxicity. ${ }^{1-3}$ Both conventional fractionation and SBRT necessitate accurate delivery of radiotherapy. ${ }^{4}$ When radiotherapy targeting is suboptimal, there is an increased risk in radiation-induced injury which is directly related to the dose delivered to normal tissue structures. ${ }^{5,6}$ Therefore, improving precision by minimizing safety margins without compromising tumor targeting should lead to a decrease in radiation toxicity.

Image-guided radiation therapy is a one approach that is used to address these issues. Techniques such as abdominal compression, accelerator beam gating with the respiratory cycle, dynamic tumor tracking, active breathing control and coaching/feedback technique are used for this purpose. Fiducial markers have been used to further improve tumor localization in lung cancer. ${ }^{7,8}$ This technique is especially useful for certain radiation delivery techniques which use $\mathrm{kV}$ imaging, such as CyberKnife (Synnyvale, CA). For these modalities, tumor is difficult to precisely visualize on imaging. In addition, fiducial markers are beneficial for cases when there is a large degree of breathing-induced tumor motion. ${ }^{9}$ While a recent singleinstitution study reported that Cyberknife radiosurgery for stage I NSCLC can be safely performed without using fiducials, this still needs to be confirmed in larger studies. ${ }^{10}$

Complications from the marker placement procedure, including pneumothorax, pneumomediastinum, infection and bleeding must be taken into account. Initially, percutaneous fiducial insertion technique was most commonly used. Unfortunately, it resulted in as high as a $60 \%$ rate of Pneumothorax. ${ }^{11}$ Endobronchial fiducial insertion and electromagnetic navigational guidance in addition to ultrasound guidance have reduced the rate of pneumothoraces to as low as $6 \%{ }^{12-15}$ This significant reduction in morbidity makes fiducial-based image guidance in NSCLC a more attractive strategy. The use of fiducial markers has been shown to be safe with outcomes similar to non-invasive tumor-tracking systems. ${ }^{16}$ Several types of fiducials are available at this time. Coils have been shown in one study to be superior to seeds as far as fiducial displacement and rate of Pneumothorax..$^{17}$ Other types of markers exist with the most recent being liquid fiducials which are actively being investigated at this time. ${ }^{18}$ Gold coil markers continue to be commonly used.

Little is known about the long-term stability and safety of fiducial markers in the lung. One recently published study showed that fiducials remained stable in 8 out of 10 patients with a follow-up from 6 to 18 months. Fiducial migration was only observed prior to the first fraction of radiotherapy. ${ }^{19}$ Unlike fiducials implanted into liver and pancreas which remain in place foryears due to the dense parenchyma of these organs, due to the lace-like lung structure it is less certain whether fiducials would remain in placeyears after their placement. In the present study, we investigated long term stability and safety of fiducial markers implanted in lung cancer patients.

\section{Methods and materials}

\section{Patient characteristics}

Seven patients with locally advanced NSCLC stages IIIA and IIIB were treated with radio chemotherapy and one patient who was not a surgical candidate with stage IB NSCLC was treated with SBRT alone. 
All eight patients had gold coil fiducial markers implanted between December 2008 and January 2011 on IRB approved protocols. See Table 1 for patient and treatment characteristics. Further details on patient characteristics and image acquisition are reported in Roman et $\mathrm{al}^{3}$

Table I Relevant patient data

\begin{tabular}{|c|c|c|c|c|c|c|c|c|c|c|c|}
\hline Name & Age & Sex & Location & Stage & Histology & GTV & $\begin{array}{l}\text { \# of } \\
\text { Markers }\end{array}$ & Guidance & $\begin{array}{l}\text { Dose and } \\
\text { Fractionation }\end{array}$ & $\begin{array}{l}\text { Concurrent } \\
\text { chemo }\end{array}$ & Survival \\
\hline $\begin{array}{l}\text { Patient } \\
\text { I }\end{array}$ & 66 & $M$ & RUL & $\begin{array}{l}\text { IIIB } \\
\text { T4N3M0 }\end{array}$ & Adenocarcinoma & 88.9 & 2 & EBUS & $\begin{array}{l}62.2 \mathrm{~Gy} \text { in } 35 \\
\text { fractions IMRT }\end{array}$ & Yes & Deceased \\
\hline $\begin{array}{l}\text { Patient } \\
2\end{array}$ & 62 & $M$ & LLL & $\begin{array}{l}\text { IIIB } \\
\text { T4N2M0 }\end{array}$ & SCC & 182.4 & 4 & EBUS & $\begin{array}{l}66 \mathrm{~Gy} \text { in } 33 \\
\text { fractions } 3 \mathrm{D} \\
\text { conformal }\end{array}$ & Yes & Deceased \\
\hline $\begin{array}{l}\text { Patient } \\
3\end{array}$ & 55 & $M$ & RUL & $\begin{array}{l}\text { IIIB } \\
\text { T4N2M0 }\end{array}$ & $\begin{array}{l}\text { Poorly- } \\
\text { differentiated }\end{array}$ & 58.3 & 2 & EBUS & $\begin{array}{l}66.6 \mathrm{~Gy} \text { in } 37 \\
\text { fractions IMRT }\end{array}$ & Yes & Deceased \\
\hline $\begin{array}{l}\text { Patient } \\
4\end{array}$ & 69 & $\mathrm{~F}$ & LLL & $\begin{array}{l}\text { IIIB } \\
\text { T2aN3M0 }\end{array}$ & $\begin{array}{l}\text { Poorly- } \\
\text { differentiated }\end{array}$ & 46.2 & 2 & EMNB & $\begin{array}{l}70 \mathrm{~Gy} \text { in } 35 \\
\text { fractions IMRT }\end{array}$ & Yes & Deceased \\
\hline $\begin{array}{l}\text { Patient } \\
5\end{array}$ & 52 & $M$ & LLL & $\begin{array}{l}\text { IIIA } \\
\text { T3NIMO }\end{array}$ & $\begin{array}{l}\text { Poorly- } \\
\text { differentiated }\end{array}$ & 42.7 & 2 & EBUS & $\begin{array}{l}70 \text { Gy in } 35 \\
\text { fractions } 3 D \\
\text { conformal }\end{array}$ & Yes & Alive \\
\hline $\begin{array}{l}\text { Patient } \\
6\end{array}$ & 53 & $\mathrm{~F}$ & RUL & $\begin{array}{l}\text { IIIA } \\
\text { T3N2M0 }\end{array}$ & Adenocarcinoma & 144.2 & 3 & EBUS & $\begin{array}{l}66 G y \text { in } 33 \\
\text { fractions } 3 D \\
\text { conformal }\end{array}$ & Yes & Alive \\
\hline $\begin{array}{l}\text { Patient } \\
7\end{array}$ & 57 & $\mathrm{~F}$ & RUL & $\begin{array}{l}\text { IIIA } \\
\text { T3N2M0 }\end{array}$ & Adenocarcinoma & 59.8 & 2 & EBUS & $\begin{array}{l}63 \mathrm{~Gy} \text { in } 35 \\
\text { fractions IMRT }\end{array}$ & Yes & Deceased \\
\hline $\begin{array}{l}\text { Patient } \\
8\end{array}$ & 58 & $M$ & LLL & $\begin{array}{l}\text { IB } \\
\text { T2NOMO }\end{array}$ & SCC & 15.3 & 2 & EBUS & $\begin{array}{l}50 G y \text { in } 5 \\
\text { fractions SBRT }\end{array}$ & No & $\begin{array}{l}\text { Lost to } \\
\text { follow-up }\end{array}$ \\
\hline
\end{tabular}

Sex: $M$, male, F, female

Ethnicity: W, white, B, black SCC, squamous cell carcinoma

Tumor locations: RUL, right upper lobe, LLL, left lower lobe, GTV, gross tumor volume, measured in cubic centimeters, EBUS, endobronchial ultrasound, EMNB, electromagnetic navigational bronchoscopy, GY, gray, IMRT, intensity-modulated radiation therapy, SBRT, stereotactic body radiation therapy

\section{Fiducial marker implantation}

An experienced interventional pulmonologist R.W.S. performed the procedures with convex endobronchial ultrasound bronchoscopy guidance in all cases except for one in which electromagnetic navigational bronchoscopy (super Dimension, Medtronic, Minneapolis, MN) was used due to peripheral tumor location. Fiducial marker placement was performed under moderate sedation by using $0.35 \mathrm{~mm} \times 10$ or $20 \mathrm{~mm}$ fiducial gold coils (Visicoil, Iba Dosimetry, Reston, VA). For verification of marker placement and for treatment planning, patients underwent same-day four-dimensional computed tomography (4D CT). The markers were implanted in tumor or lymph nodes in the para-tracheal (8 markers), pre-tracheal ( 2 markers), hilar (4 markers), and intrapulmonary (5 markers) areas. Two to 4 markers (mean 2.4) were implanted in each patient. Figure 1 shows marker locations. Marker stability was monitored throughout treatment and after treatment every 3 to 6 months by follow-up diagnostic CT scans. The procedure note as well as all of the follow-up Radiation Oncology and Interventional Pulmonology notes available in the electronic medical records were reviewed in order to determine whether any short-term and long-term complications occurred. Adequate documentation was provided for all patients used in this study.

\section{Marker stability assessment}

Initial CT scans after the fiducial placement were compared with those at the last follow up. If the marker was not observed at any given follow up CT scan then dates when the coils were last seen and when they were first missing were recorded. For the cases in which markers were placed so close to each other initially that it was impossible to separate them visually, they were assumed to both remain in place unless they were clearly missing.

\section{Long-term safety of the fiducial markers}

Electronic medical records were reviewed to determine whether any safety effects resulted from the placement of gold coils. Any changes to the patients' health and the physicians' assessment were inspected for any evidence of fiducial-related long-term complications. 


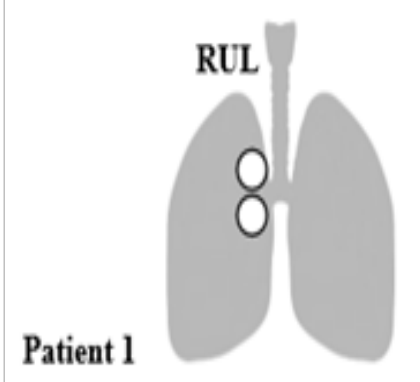

Last CT (mo): $\quad 25$

Patient 5

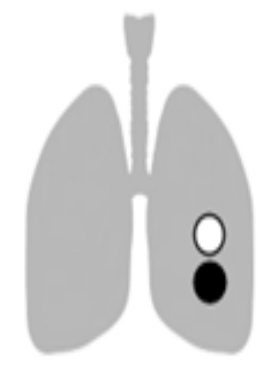

LLL

Last CT (mo): $\quad 77$
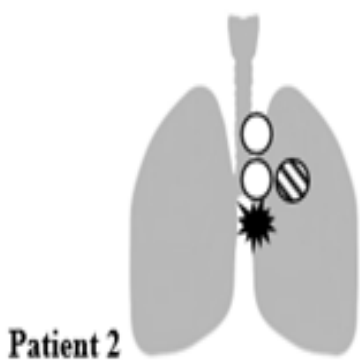

LLL

24

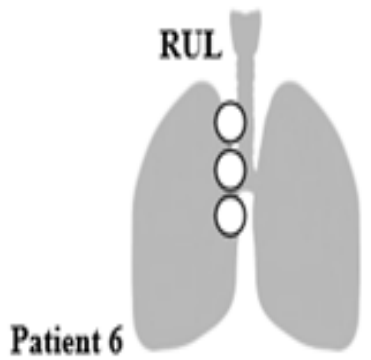

71
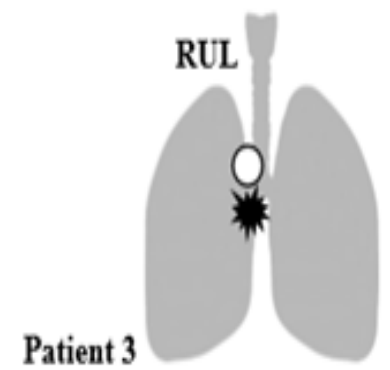

Patient 4

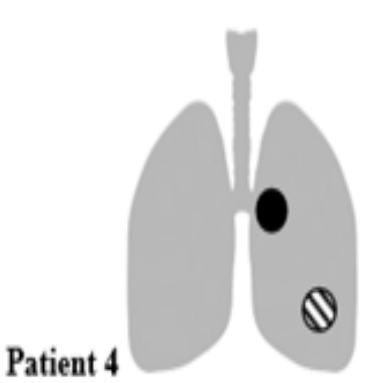

LLL

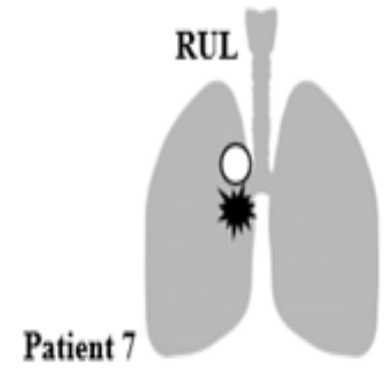

Patient 8

20
4

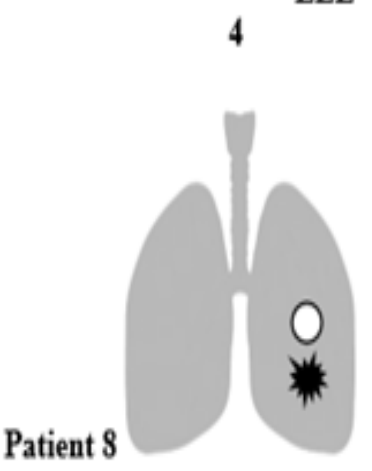

LLL
51

Figure I All implanted fiducial marker locations and stability.

, Stable.

, Dislodged during treatment.

\$. Dislodged after treatment.

, Inseparable from another coil on imaging.

Tumor locations RUL, right upper lobe and LLL, left lower lobe. “Last CT”, last ct scan obtained in a patient.

\section{Results}

\section{Marker retention}

The follow up ranged from 4months to 6years and 5months with an average of 2 years and 10 months. Two patients are confirmed to be alive free of detectable cancer progression, five patients are confirmed to be deceased and one was lost to follow-up. The last follow-up CT scans revealed that 15 out of 19 of fiducials remained in the same anatomical location long-term. Short-term marker during-treatment stability for 6 of the patients included in this study was described in Roman et al. ${ }^{3}$-two markers were expectorated during radiotherapy leaving 17 fiducials in place. The two additional patients included in the present investigation retained their fiducials throughout treatment. After radiotherapy was completed, in two patients, one of the markers was expectorated between 2 and 4months and 8 and 10months, respectively as shown in Figure 2, leaving 15 fiducials in place. In the first patient, the fiducial marker was placed in lung parenchyma with very little solid tissue support and in the second patient the coil was immediately adjacent to a large airway in a lung that has undergone significant fibrotic change and tumor resolution post-radiation therapy. Long-term retentions of coils in the same general location are illustrated in Figure 3 for the patients with the longest follow-ups (6 and 6.5years). At the last follow-up, all patients except for patient 4 had at least one fiducial in place.

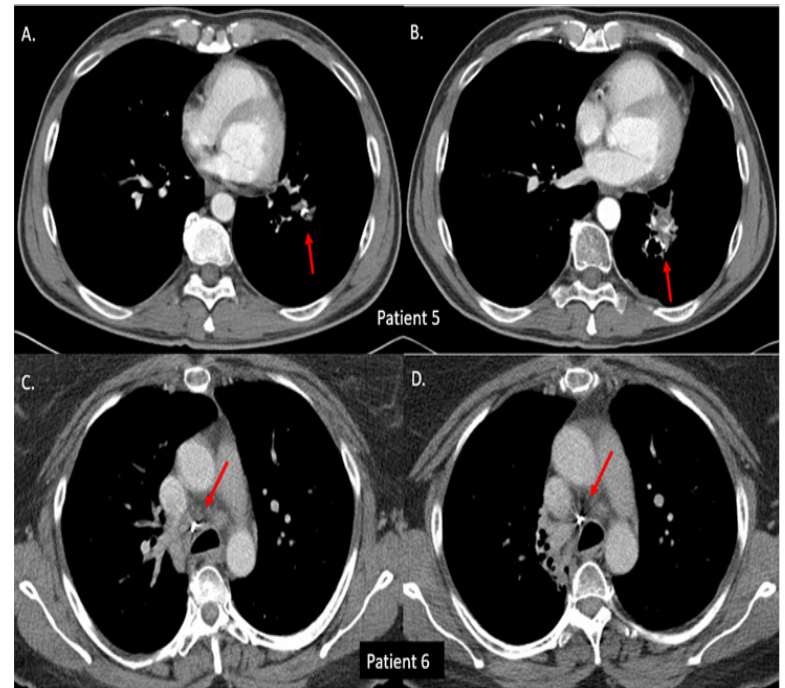

Figure 2 Coils with stable position during follow-up. Patient 5-left intrapulmonary fiducial-A. Initial placement and B. 6.5year follow-up. Note the posteromedial displacement of the coil due to fibrotic changes of the irradiated lung tissue. Patient 6-right para-tracheal fiducial-C. Initial placement and D. 6year follow-up.All three fiducial markers in this patient were visualized at 6years in the same location as the original placement. 


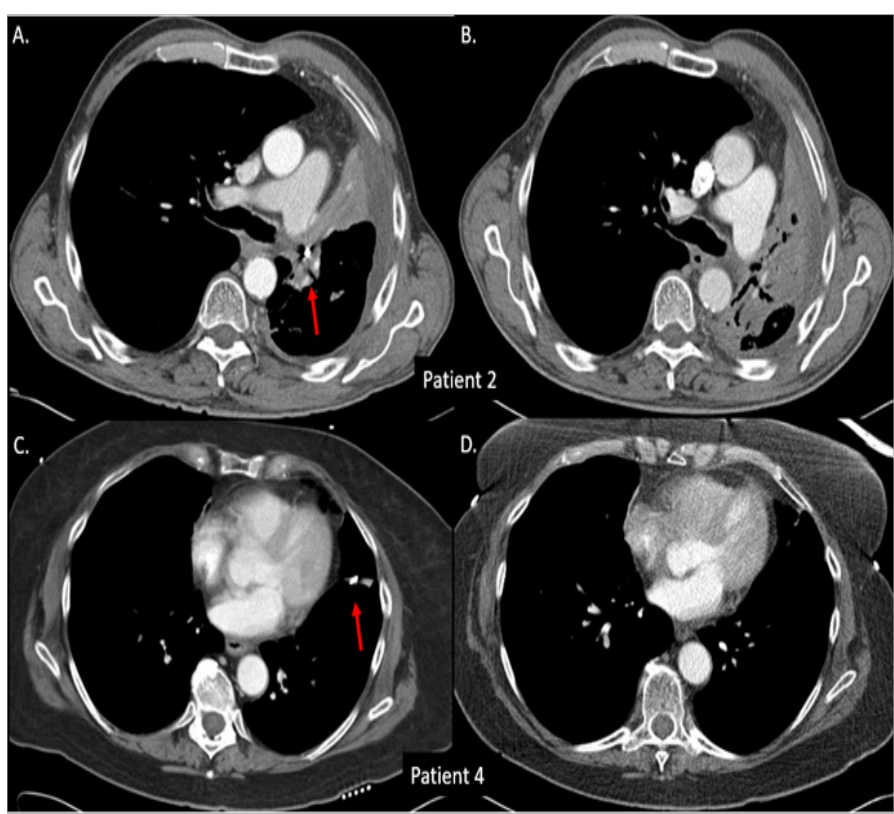

Figure 3 Coils lost after radiotherapy. Patient 2-left hilar fiducial-A. Initial placement and B. IOmonth follow-up. The marker was last seen at an 8month follow-up. Patient 4-left intrapulmonary fiducial-C. Initial placement and D. 4 month follow-up. The marker was last seen at a 2 month follow-up.

\section{Procedure safety}

The short-term safety of fiducial markers was described in Roman et al., ${ }^{3}$ for 6 of the patients included in this study and was comparable to the previous studies. The two additional patients included in the present investigation did not have any procedural complications such as pneumothorax, pneumomediastinum, bleeding or infection. From careful review of documentation, there was no evidence that fiducial placement in any way contributed to long-term toxicity or mortality. Five of the patients who are deceased died of either cancer progression or medical co-morbidities, all completely unrelated to the fiducial marker placement.

\section{Discussion}

This study shows that fiducial marker implantation was successful and safe in all eight patients. Overall retention of the gold coils was excellent with follow-up as long as 6.5years. Moreover, all markers that did not dislodge remained in either the same place or moved only slightly due to anatomic alteration secondary to tumor resolution and tissue scarring. This is the longest follow up reported for fiducial marker stability. In one prior study of 10 patients from a single institution patients were followed up to 1.5 years. ${ }^{19}$ In our patients, two markers in two separate patients out of a total of 19 markers were lost during treatment. This is comparable to the prior studies. ${ }^{9,12-15,19}$ Another two markers in two separate patients were lost at longer follow-up after radiotherapy was completed-at 4 and 10 months. One of the markers was located in the hilar region immediately adjacent to a large airway in a patient with the largest tumor in this study $(182 \mathrm{cc})$. After treatment there was a large fibrotic change and the tumor significantly shrunk, making expectoration the likely explanation for the missing coil. The other marker was placed with electromagnetic navigational guidance into lung parenchyma with very little solid tissue support. It was also likely expectorated as the marker was not noted in the pleura or elsewhere in the chest. These latter observations are interesting as loss of fiducial markers in lung cancer has not been reported several months after their original placement. Overall, the fact that most coils remained in place with a mean follow-up of 2.9years indicates that the tissue support of the markers was sufficient for very long-term retention.

Safety is a concern when it comes to fiducial marker placement. This is why it was encouraging to find that all of the patients in our institution ultimately did well from the procedure standpoint. Importantly, documentation from long-term follow-ups did not reveal any complications associated with fiducial marker placement up to 6.5years after the coil placement. This long-term safety information has never been reported.

The major limitation of this study is a small sample size. While this limits generalizability of the results, the data presented here is a proof that gold coil fiducial markers placed endobronchially can remain stable long-term and that their placement is very well-tolerated. This lends further support to this approach for image guidance in NSCLC. Fiducial markers allow for reduction in safety margin without compromising tumor coverage. ${ }^{7}$ This minimizes normal tissue dose thereby reducing the chance of developing radiation-induced lung injury, heart disease ${ }^{5,6}$ and other treatment-related side effects. Another limitation is the fact that many centers use platforms that do not use fiducial markers for NSCLC radiation therapy, limiting relevance. However, this technology is essential in centers that use systems that rely on fiducials, such as CyberKnife. In addition, the data presented here is pertinent for treatment facilities with lower-quality imaging that necessitates fiducial markers for tumor visualization. One other application of the findings presented here is re-irradiation of NSCLC local tumor recurrences..$^{20}$ The previously implanted fiducial markers may be used for repeat radiation therapy in order to both minimize patient discomfort due to a repeat marker placement and to improve the localization of the original tumor. Markers were all easy to identify on the CT scans due to high density. In addition, while records were carefully reviewed, some fiducial-related toxicity may have been missed. However, the records were complete making this unlikely. In summary, using fiducial gold coil markers for imageguided radiotherapy is a feasible strategy in NSCLC radiotherapy with excellent retention rate up to 6.5 years..$^{21,22}$

\section{Acknowledgements}

None.

\section{Author's disclosure of potential conflicts of interest}

L.R. Reshko: None. R.W. Shepherd: UpToDate, Spiration Olympus Medical, Boston Scientific Corporation. E. Weiss: UpToDate, Varian Medical Systems, Philips Medical Systems, NIH.

\section{Author contributions}

Conception and design: Leonid B. Reshko and Elisabeth Weiss

Data collection: Leonid B. Reshko and Elisabeth Weiss

Data analysis and interpretation: All authors.

Manuscript writing: All authors.

Final approval of manuscript: All authors. 


\section{References}

1. Tsang MW. Stereotactic body radiotherapy: current strategies and future development. J Thorac Dis. 2016;8(Suppl 6):S517-S527.

2. Baker S, Dahele M, Lagerwaard FJ, et al. A critical review of recent developments in radiotherapy for non-small cell lung cancer. Radiat Oncol. 2016;11(1):115.

3. Roman NO, Shepherd W, Mukhopadhyay N, et al. Interfractional positional variability of fiducial markers and primary tumors in locally advanced non-small-cell lung cancer during audiovisual biofeedback radiotherapy. Int J Radiat Oncol Biol Phys. 2012;83(5):1566-1572.

4. Giaj-Levra N, Ricchetti F, Alongi F. What is changing in radiotherapy for the treatment of locally advanced nonsmall cell lung cancer patients? A review. Cancer Investigation. 2016;34(2):80-93.

5. Palma DA, Senan S, Tsujino K, et al. Predicting radiation pneumonitis after chemoradiation therapy for lung cancer: an international individual patient data meta-analysis. Int J Radiat Oncol Biol Phys. 2013;85(2):444-450.

6. Yusuf SW, Sami S, Daher IN. Radiation-induced heart disease: a clinical update. Cardiol Res Pract. 2011;2011:317659.

7. Korreman SS. Image-guided radiotherapy and motion management in lung cancer. Br J Radiol. 2015;88(1051):20150100.

8. Nelson C, Starkschall G, Balter P, et al. Assessment of lung tumor motion and setup uncertainties using implanted fiducials. Int J Radiat Oncol Biol Phys. 2007;67(3):915-923.

9. Schroeder C, Hejal R, Linden PA. Coil spring fiducial markers placed safely using navigation bronchoscopy in inoperable patients allows accurate delivery of CyberKnife stereotactic radiosurgery. J Thorac Cardiovasc Surg. 2010;140(5):1137-1142.

10. Jung IH, Song SY, Jung J, et al. Clinical outcome of fiducial-less CyberKnife radiosurgery for stage I non-small cell lung cancer. Radiat Oncol J. 2015;33(2):89-97.

11. Bhagat N, Fidelman N, Durack JC, et al. Complications associated with the percutaneous insertion of fiducial markers in the thorax. Cardiovasc Intervent Radiol. 2010;33(6):1186-1191.

12. Kupelian PA, Forbes A, Willoughby TR, et al. Implantation and stability of metallic fiducials within pulmonary lesions. Int J Radiat Oncol Biol Phys. 2007;69(3):777-785.
13. Harley DP, Krimsky WS, Sarkar S, et al. Fiducial marker placement using endobronchial ultrasound and navigational bronchoscopy for stereotactic radiosurgery: an alternative strategy. Ann Thorac Surg. 2010;89(2):368-373.

14. Nabavizadeh N, Zhang J, Elliott DA, et al. Electromagnetic navigational bronchoscopy-guided fiducial markers for lung stereotactic body radiation therapy: analysis of safety, feasibility, and interfraction stability. $J$ Bronchology Interv Pulmonol. 2014;21(2):123-130.

15. Steinfort DP, Siva S, Kron T, et al. Multimodality guidance for accurate bronchoscopic insertion of fiducial markers. J Thorac Oncol. 2015;10(2):324-330.

16. Kelley KD, Benninghoff DL, Stein JS, et al. Medically inoperable peripheral lung cancer treated with stereotactic body radiation therapy. Radiat Oncol. 2015;10:120.

17. Hong JC, Yu Y, Rao AK, et al. High retention and safety of percutaneously implanted endovascular embolization coils as fiducial markers for image-guided stereotactic ablative radiotherapy of pulmonary tumors. Int J Radiat Oncol Biol Phys. 2011;81(1):85-90.

18. Rydhög JS, Mortensen SR, Larsen KR, et al. Liquid fiducial marker performance during radiotherapy of locally advanced non small cell lung cancer. Radiother Oncol. 2016;121(1):64-69.

19. Jackson P, Steinfort DP, Kron T, et al. Practical Assessment of Bronchoscopically Inserted Fiducial Markers for Image Guidance in Stereotactic Lung Radiotherapy. J Thorac Oncol. 2016;11(8):1363-1368.

20. Trovo M, Minatel E, Durofil E, et al. Stereotactic body radiation therapy for re-irradiation of persistent or recurrent non-small cell lung cancer. Int J Radiat Oncol Biol Phys. 2014;88(5):1114-1119.

21. Venkat RB, Sawant A, Suh Y, et al. Development and preliminary evaluation of a prototype audiovisual biofeedback device incorporating a patient-specific guiding waveform. Phys Med Biol. 2008;53(11):N197N208.

22. Lu J, Guerrero TM, Munro P, et al. Four-dimensional cone beam CT with adaptive gantry rotation and adaptive data sampling. Med Phys. 2007;34(9):3520-3529. 